\title{
PENGARUH LATIHAN TRADITIONAL PUSH UP, PL YOMETRIC PUSH UP, DAN INCLINE PUSH UP TERHADAP KEKUATAN OTOT LENGAN, POWER OTOT LENGAN, DAN DAYA TAHAN OTOT LENGAN
}

\author{
Febriyan Dwi Cahyono ${ }^{1}$, Oce Wiriawan ${ }^{2}$, dan Hari Setijono ${ }^{3}$ \\ 1,2,3 Program Studi Pendidikan Olahraga \\ Pascasarjana Universitas Negeri Surabaya \\ E-mail : febriyandwicahyono16070805002@mhs.unesa.ac.id ${ }^{1}$, \\ ocewiriawan@unesa.ac.id', harisetijono@unesa.ac.id ${ }^{3}$
}

Diterima: 10 April 2018; Lolos: 14 Mei 2018; Dipublikasikan: 18 Mei 2018

DOI: https://doi.org/10.29407/js_unpgri.v4i1.12004

Tujuan penelitian ini adalah untuk peningkatan performa fisik otot lengan siswa ekstrakulikuler putra SMAN 2 Lamongan yang memiliki kelemahan saat dilakukan evaluasi fisik. Empat puluh siswa sehat dengan melihat status gizi melalui indeks masa tubuh (IMT) dipilih sesuai dengan kriteria dan dilakukan pretest dan pemeringkatan sehingga masuk dalam pengelompokan traditional push up, plyometric push up, incline push up dan kelompok kontrol. Push up 30 detik, push up 60 detik dan medicine ball test digunakan untuk mengukur peningkatan kinerja. Ketiga kelompok berpartisipasi dalam penelitian tiga hari dalam seminggu selama enam minggu dan menyelesaikan 18 sesi pelatihan, pada frekuensi 3 sesi per minggu. Hasil uji paired sample $t$-test dalam kelompok traditional push up menunjukkan pengaruh yang signifikan pada variabel kekuatan dan daya tahan, kelompok plyometric push up menunjukkan pengaruh yang signifikan pada variabel kekuatan dan power, dan kelompok incline push up menunjukkan pengaruh yang signifikan pada variabel kekuatan dan daya tahan. Disimpulkan dari penelitian ini bahwa pelatihan traditional push up, plyometric push up dan incline push up ketiganya efektif untuk peningkatan kinerja tubuh bagian atas.

Kata kunci: Push up, latihan, kinerja fisik.

\section{THE IMPACT OF TRADITIONAL TRAINING PUSH UP, PLYOMETRIC PUSH UP, AND INCLINE PUSH UP ON IMPROVING ARM MUSCLE STRENGTH, ARM MUSCLE POWER, AND ARM MUSCLE ENDURANCE}

\begin{abstract}
The purpose of this study was to improve the physical performance of arms extracurricular students arm of SMAN 2 Lamongan students who have weaknesses during physical evaluation. Forty healthy students by looking at nutritional status through body mass index (BMI) were selected according to criteria and performed pretest and rankings so that they were included in traditional push up, plyometric push up, incline push up and control group. 30 seconds push up, 60 seconds push up and medicine ball test are used to measure performance improvement. All three groups participated in the study three days a week for six weeks and completed 18 training sessions, at a frequency of 3 sessions per week. The result of paired sample $t$-test in traditional push-up group showed significant influence on strength and endurance variables, plyometric push up group showed significant influence on strength and power variables, and incline push up group showed significant influence on strength

Email : febriyandwicahyono16070805002@mhs.unesa.ac.id @2018 UN PGRI Kediri

No Handphone : 089683269839

p-ISSN: 2548-7833

e-ISSN: $2477-3379$
\end{abstract}



Febriyan Dwi Cahyono, Oce Wiriawan, dan Hari Setijono

Pengaruh Latihan Traditional Push Up, Plyometric Push Up, dan Incline Push Up Terhadap Kekuatan Otot Lengan, Power Otot Lengan, dan Daya Tahan Otot Lengan

and power variables, and incline push up group showed significant influence on strength and endurance variables. It was concluded from this research that the training of traditional push up, plyometric push up and incline push up are effective for improving upper body performance.

Keywords: Push up, exercise, physical performance.

\section{PENDAHULUAN}

Sekolah merupakan sarana belajar bagi siswa. Belajar dalam artian suatu kegiatan dimana siswa memperoleh pengalaman baru untuk menunjang kehidupannya kelak dimasa yang akan datang. Dalam kegiatan belajar pembelajaran disekolah siswa dibekali berbagai macam hal mulai dari pembelajaran yang bersifat kognitif, afektif maupun psikomotor. Salah satu mata pelajaran yang berperan aktif mempelajari tentang kemampuan untuk bergerak adalah pendidikan jasmani dan olahraga. Mata pelajaran ini dipelajari di semua level pendidikan dasar mulai dari SD, SMP dan SMA (Burstiando \& Nurkholis, 2017). Pendidikan jasmani merupakan bagian yang tidak dapat dipisahkan dari kehidupan manusia, melalui pendidikan jasmani manusia dapat belajar lebih banyak hal yang berhubungan dengan afektif, kongnitif, dan psikomotor yang merupakan bekal manusia untuk mencapai tujuan hidup (Hanief dan Sugito, 2015).

Tujuan dari pendidikan jasmani adalah untuk meningkatkan kebugaran siswa. Siswa jika memiliki kebugaran yang baik, tidak akan mengalami kelelahan yang berarti Mahardika (2010). Dengan kemampuan kebugaran yang baik diharapkan siswa dapat menerima materi pembelajaran dengan baik sehingga menjadi siswa yang sehat dan berprestasi.

Dalam praktek dilapangan, siswa SMAN 2 Lamongan dilakukan uji kemampuan biomotor siswanya yang memilih mengikuti kegiatan ekstrakulikuler disekolahan. Kemampuan biomotor daya tahan, kekuatan dan power otot lengan menjadi kelemahan dan perlu ditingkatkan. Sehingga kemampuan biomotor kekuatan, daya tahan dan power lengan yang menjadi fokus perbaikan. 
Febriyan Dwi Cahyono, Oce Wiriawan, dan Hari Setijono

Pengaruh Latihan Traditional Push Up, Plyometric Push Up, dan Incline Push Up Terhadap Kekuatan Otot Lengan, Power Otot Lengan, dan Daya Tahan Otot Lengan

Performa yang dihasilkan dalam setiap aktivitas fisik termasuk olahraga didominasi oleh komponen biomotorik. Bompa, Tudor O \& G. Gregory Haff (2009) menjelaskan "athletic performance is dominated by combinations of strength,speed, and endurance, which are biomotor abilities“. Setiap cabang olahraga memiliki komponen biomotorik dominan.

Metode latihan yang populer di era modern sering digunakan di berbagai pusat kebugaran ataupun para pelaku olahraga yang ingin meningkatkan kebugarannya dengan menggunakan metode latihan tersebut. Contoh metode latihan yang populer di era modern ini adalah latihan pliometrik, HIIT, dan lain sebagainya.

Variasi dalam latihan dan pemilihan bentuk latihan akan menjaga siswa tetap termotivsi dan tetap fresh dalam melakukan adaptasi (Bompa, 2015:116). Hal ini yang menyebabkan pelaku olahraga semakin memperbanyak kajian dengan metode baru yang tujuan sama yaitu meningkatkan performa. Misalnya traditional push up, plyometric push up, dan incline push up merupakan bentuk latihan yang sama yaitu untuk kinerja lengan, namun semua itu berbeda metode agar latihan tidak bersifat menjemukan dan siswa bisa selalu termotivasi dalam latihan.

Metode latihan yang semakin variatif selain berefek positif terhadap peningkatan kinerja fisik seseorang, ternyata juga memberikan efek yang kurang baik bagi pelaku olahraga yang melakukan hal tersebut tanpa prosedur dan tahapan yang benar. Apalagi bagi orang awam yang hanya mengikuti tren perkembangan metode latihan tanpa mengerti tujuan dan tahapan dalam latihan tersebut dipastikan akan mengalami dampak negatif. Sesuai dengan pernyatan oleh Bompa (2015) sebuah pemahaman dari segi ilmu biomekanik dan fisiologi latihan memperlihatkan bahwa banyak produk baru tentang metode latihan tersebut yang awalnya menyatakan dapat meningkatkan kinerja fisik mungkin malah dapat merugikan mereka. Hal ini menunjukkan bahwa setiap pelaku olahraga harus lebih selektif untuk memilih metode latihan yang akan dipilih. Karena tujuan utama orang berolahraga atau latihan 
Febriyan Dwi Cahyono, Oce Wiriawan, dan Hari Setijono

Pengaruh Latihan Traditional Push Up, Plyometric Push Up, dan Incline Push Up Terhadap Kekuatan Otot Lengan, Power Otot Lengan, dan Daya Tahan Otot Lengan

adalah untuk memperoleh hasil yang memuaskan, bukan semakin menurunkan kinerja tubuh mereka.

Berlatar belakang masalah diatas peneliti memiliki pemikiran untuk menyelesaikan masalah peneliti menggunakan metode latihan push up untuk membandingkan beberapa metode latihan dikarenakan push up merupakan metode yang mudah dilakukan dan mampu diaplikasikan dengan beberapa metode latihan yang akan dibandingkan secara ilmiah.

\section{METODE}

Metode penelitian yang digunakan penulis adalah metode eksperimen semu (Quasi Eksperimen). Rancangan dalam penelitian ini menggunakan Matching-only design. Rancangan ini tidak menggunakan random sebagai cara memasukkan subjek ke dalam atau dengan yang lain berdasarkan variabel tertentu Maksum (2012). Untuk kelompok perlakuan latihan 1. Traditional push up,2. Plyometric push up, 3. Incline push up 4. Kelompok kontrol.

Tidak ada satu ketentuan absolut dalam menetukan besaran sampel untuk riset, yang penting adalah persen suatu sampel mesti bersumber dari populasi yang sudah ditentukan peneliti (Maksum, 2012). Agar memperoleh sampel yang bisa merepresentasikan dari jumlah populasi, maka dipakai rumus Sovlin untuk menentukan besaran sampel yang digunakan, sebagai berikut:

Dalam rumus Slovin dalam Mahardika (2015) taraf kesalahan yang digunakan adalah $5 \%$ atau 0,05 .

$\begin{array}{lll}\text { Rumus Slovin, yaitu : } & \mathrm{n} & =\frac{N}{1+N \mathrm{e}^{2}} \\ \text { Dimana } & \mathrm{N} & =\text { Jumlah Populasi } \\ & \mathrm{e} & =\text { Taraf Kesalahan }\end{array}$

Jumlah populasi dalam penelitian ini adalah 45 siswa putra dengan rincian sebagai berikut:
Bola basket putra
: 12 siswa
Sepakbola dan futsal
: 23 siswa
Bola Voli putra
: 10 siswa 
Setelah mengetahui jumlah populasi dalam penelitian ini, maka selanjutnya akan dilakukan rumus penentuan sampel Slovin.

$$
\begin{aligned}
\mathrm{n} & =\frac{N}{1+N e^{2}} \\
& =\frac{45}{1+45(0,05)^{2}} \\
& =\frac{45}{1+45(0,0025)} \\
& =\frac{45}{1+0,1125} \\
& =\frac{45}{1,1125} \\
& =40,45
\end{aligned}
$$

Dalam pengambilan sampel menggunakan teknik purposive sampling, menurut Mahardika (2010) teknik pengambilan sampel purposive menghendaki pengambilan sampel dengan tujuan-tujuan tertentu yang dideskripsikan sesuai dengan keperluan penelitian. Sampel diambil yang memenuhi kriteria yaitu siswa SMAN 2 Kabupaten Lamongan yang mengikuti ekstrakulikuler, berjenis kelamin putra, siswa sehat dengan indeks masa tubuh ideal dan siswa tersebut memiliki kekurangan di performa lengan. Empat puluh siswa laki-laki yang sehat dipilih dari 45 siswa yang memiliki kelemahan kemampuan biomotor kekuatan otot lengan, power otot lengan dan daya tahan otot lengan sesuai dengan kriteria dan kemudian dilakukan pretest dan pemeringkatan sehingga masuk dalam pengelompokan traditional push up (kelompok 1), plyometric push up (kelompok 2), incline push up (kelompok 3) dan kelompok kontrol (kelompok 4). Instrumen yang dipakai dalam riset ini ada tiga macam yaitu, instrumen untuk mengukur kekuatan lengan menggunakan tes push up 30 detik, untuk mengukur daya tahan otot lengan menggunakan tes push up 60 detik dan untuk mengetahui power lengan menggunakan tes medicine ball Kemenpora (2005). Ketiga kelompok perlakuan (traditional push up, plyometric push up dan incline push up) berpartisipasi dalam penelitian tiga hari dalam seminggu selama enam minggu dan menyelesaikan 18 sesi pelatihan, pada frekuensi 3 sesi per minggu. 
Febriyan Dwi Cahyono, Oce Wiriawan, dan Hari Setijono

Pengaruh Latihan Traditional Push Up, Plyometric Push Up, dan Incline Push Up Terhadap Kekuatan Otot Lengan, Power Otot Lengan, dan Daya Tahan Otot Lengan

Metode yang digunakan dalam penelitian ini adalah dengan memberikan perlakuan yang berbeda bagi tiap kelompok untuk membandingkan keefektifan latihan dari tiap metode yang akan dipilih.

\section{Kelompok I}

Selama penelitian berlangsung kegiatan yang dilakukan oleh para sampel kelompok I yaitu melakukan latihan traditional push up sesuai program latihan yang diberikan seminggu tiga kali. Cara melakukan traditional push up adalah sebagai berikut :

Lakukan di atas alas yang keras, seperti di atas lantai atau matras tipis. Kedua telapak tangan diletakkan di lantai dengan ujung jari kaki sebagai tumpuan. Untuk menjaga keseimbangan, kaki jangan terlalu menyempit melainkan dibuka melebar kira-kira selebar bahu. Jaga agar kaki, pinggang juga kepala tetap dalam keadaan lurus. Tekuk lengan bawah dan lengan atas sampai membentuk sudut 90 derajat. Lakukan gerakan tersebut berulang kali. (Azeem, 2015).

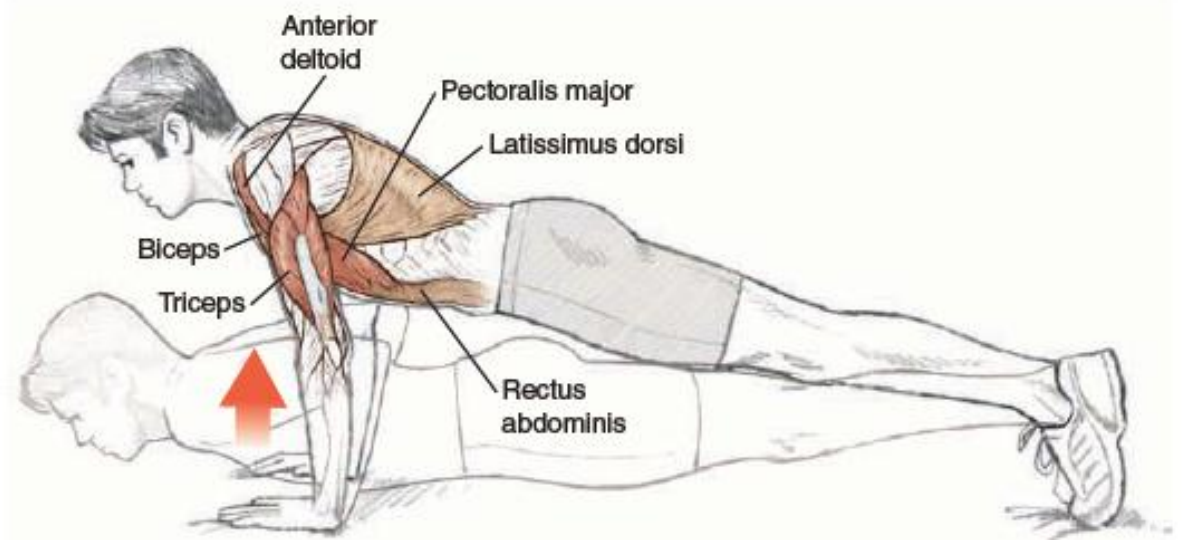

Gambar 1. Traditional Push up

\section{Kelompok II}

Selama penelitian berlangsung kegiatan yang dilakukan oleh para sampel kelompok II yaitu melakukan latihan plyometric push up sesuai program latihan yang diberikan seminggu tiga kali. Cara melakukan plyometric push up adalah sebagai berikut :

Lakukan di atas alas yang keras, seperti di atas lantai atau matras tipis. Kedua telapak tangan diletakkan di lantai dengan ujung jari kaki 
Febriyan Dwi Cahyono, Oce Wiriawan, dan Hari Setijono

Pengaruh Latihan Traditional Push Up, Plyometric Push Up, dan Incline Push Up Terhadap Kekuatan Otot Lengan, Power Otot Lengan, dan Daya Tahan Otot Lengan

sebagai tumpuan. Untuk menjaga keseimbangan, kaki jangan terlalu menyempit melainkan dibuka melebar kira-kira selebar bahu. Jaga agar kaki, pinggang juga kepala tetap dalam keadaan lurus. Tekuk lengan bawah dan lengan atas sampai membentuk sudut 90 derajat.Ketika posisi sudah membentuk 90 derajat, dorong dan hentakkan ke atas sehingga telapak tangan meninggalkan alas atau lantai. Setelah berada di udara, sesegera mungkin telapak tangan bersiap kembali mendarat seperti saat awal sebelum lengan ditekuk. Lakukan gerakan tersebut berulang kali. Kumar (2015).



Gambar 2. Plyometric Push Up

\section{Kelompok III}

Selama penelitian berlangsung kegiatan yang dilakukan oleh para sampel kelompok III yaitu melakukan latihan incline push up sesuai program latihan yang diberikan seminggu tiga kali. Cara melakukan incline push up adalah sebagai berikut:

Ulmer (2006) incline push up adalah latihan push-up yang digunakan untuk membangun kekuatan dasar pada otot dada, otot lengan, dan otot bahu. Posisi miring pada push-up ini akan mengurangi ketegangan pada tubuh bagian atas. Push-up dengan bangku memerlukan otot stabilizer yang lebih kecil di bahu dan mempertahankan 
Febriyan Dwi Cahyono, Oce Wiriawan, dan Hari Setijono

Pengaruh Latihan Traditional Push Up, Plyometric Push Up, dan Incline Push Up Terhadap Kekuatan Otot Lengan, Power Otot Lengan, dan Daya Tahan Otot Lengan

gerakan postur tubuh selama latihan. Komponen otot yang terlibat dalam gerakan ini antara lain sternum pectoralis major, pectoralis klavikularis major, trisep dan bisep. Otot-otot ini sangat penting untuk mendukung sendi dan mencegah cedera.

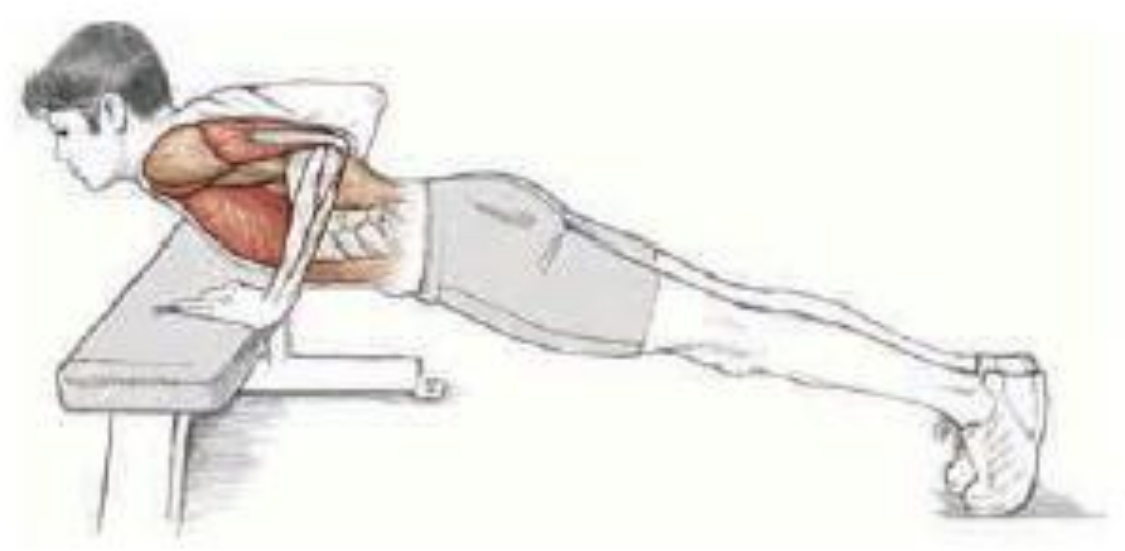

Gambar 3. Latihan Incline Push up

\section{Kelompok IV}

Kelompok ini adalah kelompok kontrol yang melakukan kegiatan seperti biasa atau latihan konvensional tanpa ada perlakuan.

Tabel 1. Program Latihantraditional Push up, Plyometric Push up Dan Incline Push up

\begin{tabular}{|c|c|c|c|c|}
\hline Minggu & Pertemuan & Intensitas & Set & Rest \\
\hline \multirow{3}{*}{1} & 1 & $50 \%$ & 3 & 2 menit \\
\hline & 2 & $50 \%$ & 3 & 2 menit \\
\hline & 3 & $50 \%$ & 3 & 2 menit \\
\hline \multirow{3}{*}{2} & 4 & $50 \%$ & 3 & 2 menit \\
\hline & 5 & $50 \%$ & 3 & 2 menit \\
\hline & 6 & $50 \%$ & 3 & 2 menit \\
\hline \multirow{3}{*}{3} & 7 & $60 \%$ & 3 & 2 menit \\
\hline & 8 & $60 \%$ & 3 & 2 menit \\
\hline & 9 & $60 \%$ & 3 & 2 menit \\
\hline \multirow{2}{*}{4} & 10 & $60 \%$ & 3 & 2 menit \\
\hline & 11 & $60 \%$ & 3 & 2 menit \\
\hline
\end{tabular}


Febriyan Dwi Cahyono, Oce Wiriawan, dan Hari Setijono

Pengaruh Latihan Traditional Push Up, Plyometric Push Up, dan Incline Push Up Terhadap Kekuatan Otot Lengan, Power Otot Lengan, dan Daya Tahan Otot Lengan

\begin{tabular}{lllll} 
& 12 & $60 \%$ & 3 & 2 menit \\
\hline \multirow{3}{*}{5} & 13 & $70 \%$ & 3 & 2 menit \\
\cline { 2 - 5 } & 14 & $70 \%$ & 3 & 2 menit \\
\cline { 2 - 5 } & 15 & $70 \%$ & 3 & 2 menit \\
\hline \multirow{2}{*}{6} & 16 & $70 \%$ & 3 & 2 menit \\
\cline { 2 - 5 } & 17 & $70 \%$ & 3 & 2 menit \\
\hline & 18 & $70 \%$ & 3 & 2 menit
\end{tabular}

Sumber : (Bompa,2015)

Untuk menciptakan sebuah program latihan kekuatan yang sukses, maka pelatih dan atlet akan menipulasi beberapa variable latihan, seperti volume dan intensitas latihan Bompa (2015). Hanya sedikit atlet yang mampu melakukan latihan kekuatan dengan beban supermaksimal, itu pun karena mereka memiliki latar belakang latihan kekuatan yang baik. Tiap zona intensitas yang dipilih atlit akan memperlihatkan adaptasi neuromuscular yang berbeda. Dalam latihan beban yang dilakukan dalam penelitian ini menggunakan 50-70\% repetisi maksimal Bompa (2015). Pemilihan beban rendah ke medium 50-70\% repetisi maksimal dikarenakan penelitian ini memiliki 3 variabel terikat yaitu kekuatan, power dan daya tahan otot.

Penentuan set latihan harus melihat aspek repetisi latihan hal ini dikarenakan jika jumlah repetisi yang tinggi, maka atlit tersebut akan memiliki kesulitan dalam melakukan set lebih dari tiga Bompa (2015)

Semua program latihan kekuatan periodisasi dimulai dengan sebuah fase adaptasi anatomi yang mempersiapkan tubuh untuk fase latihan yang akan diikutinya Bompa (2015). Latihan tersebut dilakukan selama 6 minggu dikarenakan, menurut Bompa (2015) latihan akan efektif jika dilakukan selama empat sampai delapan minggu.

Teknik analisis data yang digunakan adalah: 1) Analisis data deskriptif, untuk mengetahui frekuensi, prosentase, serta rerata 2) Analisis data dilakukan dengan menggunakan program SPSS 21. Menghitung uji normalitas data dalam penelitian ini dilakukan uji Kolmogorov-Smirnov bila perolehan data normal dilanjutkan dengan uji paired sample t-test, 
Febriyan Dwi Cahyono, Oce Wiriawan, dan Hari Setijono

Pengaruh Latihan Traditional Push Up, Plyometric Push Up, dan Incline Push Up Terhadap Kekuatan Otot Lengan, Power Otot Lengan, dan Daya Tahan Otot Lengan

kemudian uji homogenitas dan ANOVA untuk mengetahui metode latihan mana yang paling efektif untuk meningkatakan kinerja fisik otot lengan.

\section{HASIL DAN PEMBAHASAN}

\section{Hasil}

a. Deskriptif data

Terdapat tiga variabel yang diujikan pada keempat kelompok dalam penelitian ini, yaitu variabel kekuatan, daya tahan dan power otot terhadap tiga kelompok perlakuan yaitu kelompok yaitu traditional push up, plyometric push up, dan incline push up. Sedangkan satu kelompok lainnya tidak diberikan perlakuan yaitu kelompok kontrol. Dalam tabel berikut ini akan dijabarkan hasil deskriptiv data yang telah dianalisis melalui aplikasi SPSS 21.

Tabel 2 Deskriptif Rata-Rata Data Sebelum dan Sesudah Penelitian

\begin{tabular}{clcccc} 
& \multicolumn{1}{c}{ Statistik } & $\mathrm{N}$ & Pre & Pos & Selisih \\
\hline \multirow{2}{*}{$\begin{array}{c}\text { Traditional } \\
\text { Push up }\end{array}$} & Kekuatan & 10 & 17,5 & 20,6 & 3,10 \\
\cline { 2 - 6 } & daya_tahan & 10 & 23,1 & 25,8 & 2,70 \\
\cline { 2 - 6 } & Power & 10 & 109,0 & 110,0 & 1,00 \\
\hline \multirow{2}{*}{$\begin{array}{c}\text { Plyometric } \\
\text { Push up }\end{array}$} & Kekuatan & 10 & 15,7 & 17,7 & 2,00 \\
\cline { 2 - 6 } & daya_tahan & 10 & 21,4 & 22,0 & 0,60 \\
\cline { 2 - 6 } Incline Push & Power & 10 & 119,9 & 123,4 & 3,50 \\
\cline { 2 - 6 } up & Kekuatan & 10 & 15,4 & 18,3 & 2,90 \\
\cline { 2 - 6 } & daya_tahan & 10 & 23,1 & 26,5 & 3,40 \\
\hline \multirow{2}{*}{ Kontrol } & Kower & 10 & 114,7 & 114,7 & 0,00 \\
\cline { 2 - 6 } & daya_tahan & 10 & 22,6 & 23,1 & 0,50 \\
\cline { 2 - 5 } & Power & 10 & 113,2 & 113,6 & 0,40
\end{tabular}

Dari data tabel 2 diatas dapat kita simpulkan bahwa semua kelompok mengalami peningkatan namun peningkatan rerata setelah diberikan perlakuan. Namun dalam tabel tersebut kelompok kontrol tidak memiliki peningkatan yang besar. 
Febriyan Dwi Cahyono, Oce Wiriawan, dan Hari Setijono

Pengaruh Latihan Traditional Push Up, Plyometric Push Up, dan Incline Push Up Terhadap Kekuatan Otot Lengan, Power Otot Lengan, dan Daya Tahan Otot Lengan

b. Normalitas data

Uji normalitas memiliki tujuan untuk mengetahui apakah skor yang diperoleh sampel berdistribusi normal atau tidak. Uji normalitas distribusi menggunakan shapiro wilk. Untuk lebih jelasnya akan dijabarkan sebagai berikut .

Tabel 3 Normalitas Skor Pre Test

\section{Tests of Normality}

\begin{tabular}{clll}
\hline \multirow{2}{*}{ Kelompok } & \multicolumn{2}{c}{ Shapiro-Wilk } & \\
\hline \multirow{3}{*}{ Traditional Push up } & Kekuatan & Sig. & Keterangan \\
\cline { 2 - 4 } & Daya tahan &, 818 & Normal \\
\cline { 2 - 4 } & Power &, 771 & Normal \\
\hline \multirow{3}{*}{ Plyometric Push up } & Kekuatan &, 740 & Normal \\
\cline { 2 - 4 } & Daya tahan &, 793 & Normal \\
\cline { 2 - 4 } Incline Push up & Power &, 237 & Normal \\
\cline { 2 - 4 } & Kekuatan &, 631 & Normal \\
\cline { 2 - 4 } & Power tahan &, 927 & Normal \\
\hline Kontrol & Kekuatan &, 118 & Normal \\
\cline { 2 - 4 } & Daya tahan &, 071 & Normal \\
\cline { 2 - 4 } & Power &, 462 & Normal
\end{tabular}

Berdasarkan penjabaran pada tabel 3 diketahui bahwa seluruh skor pre test dari seluruh kelompok berdistribusi normal karena sig. > 0,05.

Tabel 4 Normalitas Skor Post Test

Tests of Normality

\begin{tabular}{clcc}
\hline \multirow{4}{c}{ Shapiro-Wilk } \\
\hline Kelompok & \multicolumn{1}{c}{ Variabel } & Sig. & Keterangan \\
\hline \multirow{2}{*}{$\begin{array}{c}\text { Traditional } \\
\text { Push up }\end{array}$} & Kekuatan &, 728 & Normal \\
\cline { 2 - 4 } & Daya tahan &, 546 & Normal \\
\cline { 2 - 4 } & Power &, 320 & Normal
\end{tabular}


Febriyan Dwi Cahyono, Oce Wiriawan, dan Hari Setijono

Pengaruh Latihan Traditional Push Up, Plyometric Push Up, dan Incline Push Up Terhadap Kekuatan Otot Lengan, Power Otot Lengan, dan Daya Tahan Otot Lengan

\begin{tabular}{clll} 
Plyometric & \multicolumn{1}{l}{ Kekuatan } &, 446 & Normal \\
\cline { 2 - 4 } \begin{tabular}{c} 
Push up \\
\cline { 2 - 3 } Incline Push up
\end{tabular} & Daya tahan &, 665 & Normal \\
\cline { 2 - 4 } & Power &, 287 & Normal \\
\cline { 2 - 4 } & Daya tahan &, 796 & Normal \\
\cline { 2 - 4 } & Power &, 195 & Normal \\
\hline \multirow{2}{*}{ Kontrol } & Kekuatan &, 169 & Normal \\
\cline { 2 - 4 } & Daya tahan &, 781 & Normal \\
\cline { 2 - 4 } & Power &, 470 & Normal
\end{tabular}

Berdasarkan penjabaran pada tabel 4 diketahui bahwa seluruh skor post test dari seluruh kelompok berdistribusi normal karena sig. $>0,05$.

Tabel 5 Normalitas Skor Delta

Tests of Normality

\begin{tabular}{clrl}
\hline \multicolumn{4}{c}{ Shapiro-Wilk } \\
\hline Kelompok & \multicolumn{1}{c}{ Variabel } & Sig. & Keterangan \\
\hline \multirow{2}{*}{$\begin{array}{c}\text { Traditional } \\
\text { Push up }\end{array}$} & Kekuatan &, 646 & Normal \\
\cline { 2 - 4 } & Daya tahan &, 496 & Normal \\
\cline { 2 - 4 } & Power &, 341 & Normal \\
\hline \multirow{2}{*}{$\begin{array}{c}\text { Plyometric } \\
\text { Push up }\end{array}$} & Kekuatan &, 591 & Normal \\
\cline { 2 - 4 } & Daya tahan &, 849 & Normal \\
\cline { 2 - 4 } Incline Push & Power &, 849 & Normal \\
\cline { 2 - 4 } up & Kekuatan &, 849 & Normal \\
\cline { 2 - 4 } & Daya tahan &, 447 & Normal \\
\hline \multirow{2}{*}{ Kontrol } & Kower &, 646 & Normal \\
\cline { 2 - 4 } & Daya tahan &, 591 & Normal \\
\cline { 2 - 4 } & Power &, 458 & Normal \\
\hline
\end{tabular}

Berdasarkan penjabaran pada tabel 5 diketahui bahwa seluruh skor dari seluruh kelompok berdistribusi normal karena sig. > 0,05.

c. Homogenitas data

Uji homogenitas digunakan untuk mengetahui apakah sampel yang digunakan memiliki varians yang sama. 
Febriyan Dwi Cahyono, Oce Wiriawan, dan Hari Setijono

Pengaruh Latihan Traditional Push Up, Plyometric Push Up, dan Incline Push Up Terhadap Kekuatan Otot Lengan, Power Otot Lengan, dan Daya Tahan Otot Lengan

Tabel 6 Homogenitas Skor Delta

Test of Homogeneity of Variances

\begin{tabular}{ccc}
\hline & Sig. & Ket \\
\hline delta_kekuatan &, 952 & homogen \\
\hline delta_dayatahan &, 858 & homogen \\
\hline delta_power &, 350 & homogen
\end{tabular}

Berdasarkan tabel 6 diatas diketahui bahwa data seluruh variabel dinyatakan homogen karena nilai sig. > 0,05.

d. Uji beda

Untuk menguji apakah terdapat pengaruh dari perlakuan (treatment) terhadap variabel yang digunakan maka dilakukan paired $t$ test. Berikut ini akan dijabarkan hasil penelitian uji beda tiap kelompok.

Hipotesis :

$\mathrm{H}_{\mathrm{o}} \quad$ : Tidak terdapat pengaruh dari pemberian perlakuan

$\mathrm{H}_{1} \quad$ : Terdapat pengaruh dari pemberian perlakuan

Kriteria pengujian

$\mathrm{H}_{0}$ ditolak dan $\mathrm{H}_{1}$ diterima jika Sig. > 0,05

$\mathrm{H}_{\mathrm{o}}$ ditolak dan $\mathrm{H}_{1}$ ditolak jika Sig. > 0,05

Tabel 7 Uji Beda Kelompok Traditional push up

Paired Samples Test

\begin{tabular}{clr}
\hline & & Sig. (2-tailed) \\
\hline \multirow{2}{*}{$\begin{array}{c}\text { Traditional Push } \\
\text { up }\end{array}$} & Pre - Pos Kekuatan &, 000 \\
\cline { 2 - 3 } & Pre - Pos Daya Tahan &, 002 \\
\cline { 2 - 3 } & Pre - Pos Power &, 063
\end{tabular}

Dari data tabel 7 signifikasi yang didapatkan oleh kekuatan 0,000 dan daya tahan 0,002 atau Sig. $<0,05$ maka terdapat pengaruh signifikan latihan traditional push up terhadap peningkatan kekuatan dan daya tahan otot lengan. Signifikasi oleh power 0,0063 atau sig. > 0,05 maka tidak terdapat pengaruh yang signifikan latihan traditional push up terhadap peningkatan power otot lengan. 
Febriyan Dwi Cahyono, Oce Wiriawan, dan Hari Setijono

Pengaruh Latihan Traditional Push Up, Plyometric Push Up, dan Incline Push Up Terhadap Kekuatan Otot Lengan, Power Otot Lengan, dan Daya Tahan Otot Lengan

Tabel 8 Uji Beda Kelompok plyometric push up

Paired Samples Test

\begin{tabular}{llr}
\hline & & Sig. (2-tailed) \\
\hline \multirow{2}{*}{ Plyometric Push up } & Pre - Pos Kekuatan &, 002 \\
\cline { 2 - 3 } & Pre - Pos Daya Tahan &, 343 \\
\cline { 2 - 3 } & Pre - Pos Power &, 000
\end{tabular}

Dari data tabel 8 signifikasi yang didapatkan oleh kekuatan 0,002 dan power 0,000 atau sig. < 0,05 maka terdapat pengaruh signifikan latihan plyometric push up terhadap peningkatan kekuatan dan power otot lengan. Signifikasi oleh daya tahan 0,343 atau Sig. > 0,05 maka tidak terdapat pengaruh yang signifikan latihan plyometric push up terhadap peningkatan daya tahan otot lengan.

Tabel 9 Uji Beda Kelompok incline push up

Paired Samples Test

\begin{tabular}{llr}
\hline & & Sig. (2-tailed) \\
\hline \multirow{3}{*}{ Incline Push up } & Pre - Pos Kekuatan &, 000 \\
\cline { 2 - 3 } & Pre - Pos Daya Tahan &, 001 \\
\cline { 2 - 3 } & Pre - Pos Power &, 121
\end{tabular}

Dari data tabel 9 signifikasi yang didapatkan oleh kekuatan 0,000 dan daya tahan 0,001 atau sig. < 0,05 maka terdapat pengaruh signifikan latihan incline push up terhadap peningkatan kekuatan dan daya tahan otot lengan. Signifikasi oleh power 0,121 atau sig. > 0,05 maka tidak terdapat pengaruh yang signifikan latihan incline push up terhadap peningkatan power otot lengan.

Tabel 10 Uji Beda Kelompok kontrol

Paired Samples Test

\begin{tabular}{llr}
\hline \multirow{3}{*}{ Kontrol } & Sig. (2-tailed) \\
\cline { 2 - 3 } & Pre - Pos Kekuatan &, 479 \\
\cline { 2 - 3 } & Pre - Pos Daya Tahan &, 363 \\
\cline { 2 - 3 } & Pre Power &, 613
\end{tabular}


Dari data tabel 10 signifikasi yang didapatkan oleh kekuatan 0,479, daya tahan 0,363 dan power 0,613 atau sig. > 0,05 maka tidak terdapat pengaruh yang signifikan kelompok kontrol terhadap peningkatan kekuatan, daya tahan dan power otot lengan.



Gambar 4. Perbedaan Hasil Pretest Dan Posttest Kemampuan Biomotor Kekuatan

Berdasarkan gambar 4 diatas diketahui bahwa peningkatan kekuatan otot lengan paling tinggi terdapat pada kelompok traditional push up. Sedangkan pada kelompok kontrol memiliki peningkatan paling rendah. Selanjutnya akan disajikan diagram komponen biomotor power otot lengan.

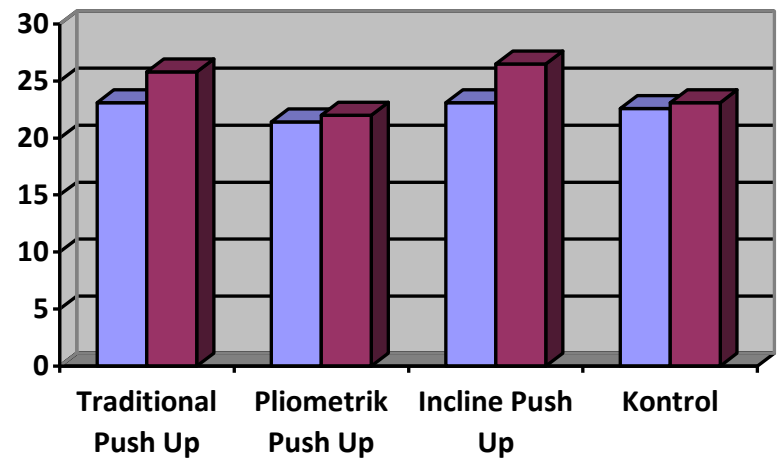

Gambar 5. Perbedaan Hasil Pre Test Dan Post Test Kemampuan Biomotor Power 
Febriyan Dwi Cahyono, Oce Wiriawan, dan Hari Setijono

Pengaruh Latihan Traditional Push Up, Plyometric Push Up, dan Incline Push Up Terhadap Kekuatan Otot Lengan, Power Otot Lengan, dan Daya Tahan Otot Lengan

Berdasarkan gambar 5 diatas diketahui bahwa peningkatan power otot lengan paling tinggi terdapat pada kelompok plyometric push up. Sedangkan pada kelompok kontrol memiliki peningkatan paling rendah. Selanjutnya akan disajikan diagram komponen biomotor daya tahan otot lengan.



Gambar 6. Perbedaan Hasil Pretest Dan Posttest Kemampuan Biomotor Daya Tahan

Berdasarkan gambar 6 diatas diketahui bahwa peningkatan power otot lengan paling tinggi terdapat pada kelompok incline push up. Sedangkan pada kelompok plyometric push up memiliki peningkatan paling rendah.

\section{Pembahasan}

Siswa yang memiliki kemampuan dan keterampilan olahraga dalam lembaga pendidikan diberikan fasilitas untuk menyalurkan bakatnya dalam kegiatan ekstrakulikuler olahraga. Selain kemampuan biomotor yang diharapkan mampu meningkat, melalui media ekstrakulikuler juga diharapkan siswa mampu memperoleh prestasi dalam bidang olahraga. Hal ini juga harus didukung dengan latihan yang teratur dan berprogres.

Menurut Clark (2004) latihan dapat mengurangi risiko kematian. Hal ini dikarenakan aktivitas bukanlah kegiatan yang terkonsep seperti latihan. Latihan yang memiliki berbagai macam metode selalu menunjukkan perkembangan konsep yang benar dalam melakukan gerakan dan pelaksanaanya. 
Febriyan Dwi Cahyono, Oce Wiriawan, dan Hari Setijono

Pengaruh Latihan Traditional Push Up, Plyometric Push Up, dan Incline Push Up Terhadap Kekuatan Otot Lengan, Power Otot Lengan, dan Daya Tahan Otot Lengan

Dalam latihan traditional push up kemampuan biomotor yang bisa meningkat adalah kemampuan biomotor kekuatan dan daya tahan. Kemudian latihan plyometric push up mampu meningkatkan kemampuan biomotor kekuatan dan power. Sedangkan latihan incline push up mampu meningkatkan kemamuan kekuatan dan daya tahan otot lengan.

Latihan traditional push up, plyometric push up dan incline push up ketiganya efektif untuk peningkatan kinerja tubuh bagian atas. Sesuai dengan penelitian sebelumnya bahwa latihan yang dilakukan selama enam minggu mampu memberikan efek yang signifikan pada peningkatan kekuatan dan plyometric pada tubuh bagian atas siswa Jenifer (2015).

Penelitian ini merupakan penelitian eksperimen yang bersifat action research, hal ini dikarenakan pada penelitian ini menjawab dari permasalahan yang timbul dalam evaluasi kemampuan biomotor siswa SMAN 2 Lamongan. Setelah melakukan evaluasi, ditemukan beberapa siswa yang memiliki kelemahan dalam komponen biomotor lengan, yaitu kekuatan, power dan daya tahan. Sehingga dilakukan penelitian untuk menguji metode mana yang mampu memberikan peningkatan kemampuan biomotor tersebut. Banyak penelitian yang menguji metode peningkatan kemampuan biomotor, namun penelitian ini memiliki kelebihan, hal ini dikarenakan penelitian ini menggunakan metode latihan yang beragam dan menggunakan otot lengan berbeda dengan penelitian lain yang cenderung menggunakan otot tungkai sebagai metode perlakuan. Contoh kebaharuan dalam penelitian ini adalah dalam penelitian Kumar, P., Vishen, S., \& Sen, S. yang berjudul Comparision of dynamic push- up training and plyometric push-up training on upper body performance test in cricket Player. Menggunakan dua metode bebas yaitu dynamic push up dan pliometrik push up, namun dalam penelitian ini menggunakan tiga veriabel bebas dan terikat yaitu tradisional push up, plyometric push up dan incline push up. Metode incline push up menjadi pemilihan tambahan variabel dalam perlakuan atau variabel bebas dikarenakan melihat tujuan dari pemilihan metode push up itu sendiri yaitu sesuai dengan pendapat Hsu (2011) Latihan push-up merupakan latihan 
Febriyan Dwi Cahyono, Oce Wiriawan, dan Hari Setijono

Pengaruh Latihan Traditional Push Up, Plyometric Push Up, dan Incline Push Up Terhadap Kekuatan Otot Lengan, Power Otot Lengan, dan Daya Tahan Otot Lengan

yang nyaman, mudah dipelajari, dan mudah disesuaikan dengan berbagai tingkat kesulitan. Akibatnya, mereka umumnya dilakukan oleh individu yang sadar kesehatan dan atlet untuk memperkuat otot-otot ekstremitas atas. Penyesuaian sudut ketinggian incline membuat siswa mudah beradaptasi terlebih dulu tentang metode latihan push up. Sehingga repetisi yang dilakukan saat melakukan incline push up lebih banyak.

\section{KESIMPULAN}

Dalam variabel kekuatan dan power terdapat perbedaan efek terhadap ketiga metode latihan. Pada variabel kekuatan metode traditional push up semua kelompok perlakuan memberi pengaruh yang lebih efektif sedangkan variabel power metode latihan plyometric push up memberi pengaruh lebih efektif. Namun dapat dsimpulkan dari penelitian ini bahwa latihan traditioanal push up, plyometric push up dan incline push up ketiganya efektif untuk peningkatan kinerja tubuh bagian atas pada siswa SMAN 2 Lamongan.

\section{DAFTAR PUSTAKA}

Azeem, Kaukab (2015). The Push-Up. International Journal of Fitness, Health, Physical Education \& Iron Games, (2)1, Jan 2015- June 2015.

Bompa, T., \& Buzzichelli, C. (2015). Periodization Training for Sports-3rd Edition. Retrieved from https://books.google.com/books?id=Zb7GoAEACAAJ\&pgis=1 .

Bompa, T.O and Haff, G.G. (2009). Periodezation Theory and Methodology of Training. New York: Human Kinetics.

Burstiando, R., \& Nurkholis, M. (2018). Permainan Invasi dan Permainan Netting untuk Meningkatkan Keterampilan Gerak Dasar Fundamental Siswa SD Negeri Se Kecamatan Mojoroto Kota Kediri. Jurnal SPORTIF : Jurnal Penelitian Pembelajaran, 3(2), 167-177. doi:10.29407/js_unpgri.v3i2.11892.

Clark, Michael A., Lucett, Scott., Corn, Rodney., Cappuccio, Robert., Humphrey, Reed., Kraus, J. S., Titchenal, Alam., Robbins, Paul. 
Febriyan Dwi Cahyono, Oce Wiriawan, dan Hari Setijono

Pengaruh Latihan Traditional Push Up, Plyometric Push Up, dan Incline Push Up Terhadap Kekuatan Otot Lengan, Power Otot Lengan, dan Daya Tahan Otot Lengan

(2004). Optimum Performance Training for the Health and Fitness Professional (NASM's Course Manual). USA.

Hsu, H. H., Chou, Y. L., Huang, Y. P., Huang, M. J., Lou, S. Z., \& Chou, P. P. H. (2011). Effect of push up speed on upper extremity training until fatigue. Journal of Medical and Biological Engineering, 31(4), 289-293. https://doi.org/10.5405/jmbe.844.

Inovero, J. G., \& Pagaduan, J. C. (2015). Effects of a Six-Week Strength Training and Upper Body Plyometrics in Male College Basketball Physical Education Students. Sport Scientific \& Practical Aspects, 12(1), 11-16.

Kemenpora RI. (2005). Panduan Penetapan Parameter Tes Pusat Pendidikan dan Pelatihan Pelajar dan Sekolah Khusus Olahragawan. Jakarta.

Kumar, P., Vishen, S., \& Sen, S. (2015). Comparision of dynamic push- up training and plyometric push-up training on upper body performance test in cricket Player, 2(1), 199-203.

Mahardika, I Made Sriundy. (2010). Pengantar Evaluasi Pengajaran. Surabaya : Unesa University Press.

Mahardika, I Made Sriundy. (2015). Metodologi Penelitian. Surabaya : Unesa University Press.

Maksum, Ali. (2012). Metodologi Pendidikan. Surabaya: Unesa University Press.

Ulmer, G. (2006, May 24). Diakses May 11, 2018, dari What Are the Benefits of Incline Pushups?: https://healthyliving.azcentral.com/benefits-incline-pushups2688.html.

Wirnantika, I., Pratama, B., \& Hanief, Y. (2017). Survey Tingkat Kebugaran Jasmani Siswa Kelas IV SDN Puhrubuh I dan MI Mambaul Hikam di Kabupaten Kediri Tahun Ajaran 2016/2017. Jurnal SPORTIF : Jurnal Penelitian Pembelajaran, 3(2), 240-250. doi:10.29407/js_unpgri.v3i2.11898. 